\title{
Simile and Metaphor Interpretation in Children
}

\author{
Yusi Song $^{1}$ \\ ${ }^{1}$ Leshan Normal University, Leshan, China \\ Correspondence: Yusi Song, School of Foreign Languages, Leshan Normal University, Leshan, China.
}

Received: February 19, 2020

Accepted: March 23, 2020

Online Published: March 24, 2020

doi: 10.5539/elt.v13n4p91

URL: https://doi.org/10.5539/elt.v13n4p91

\begin{abstract}
Metaphors and similes have been treated as the same comparable types of figurative speech since Aristotle. In early theories, metaphors are interpreted as corresponding similes by paraphrasing. Based on this theoretical framework, some experimental studies interpret simile understanding as evidence for metaphor understanding. However, according to Relevance Theory, similes are interpreted as comparisons, whereas metaphors are interpreted as categorization statements. Therefore, only metaphor reveals metaphor interpretation. In other words, studies cannot use simile interpretation as evidence for metaphor interpretation ability in children. Simile should be easier to understand for children since they exclude an "ad hoc concept" construction as in metaphor understanding. This study seeks evidence showing children's better performance in simile interpretation than that in metaphor interpretation, thus supporting Relevance Theory. For the Relevance Theory account, whether the experiments use similes or metaphors as testing materials is of considerable significance, whereas for comparison account, it is not. By review and re-interpretation of the empirical studies, we find that few early studies expose "real metaphor" understanding in children. Most experimental results indicate that simile interpretation is easier than metaphor interpretation for children. We consider comparison theory and the Relevance Theory as complementary strategies in metaphor interpretation.
\end{abstract}

Keywords: categorization theory, comparison theory, figurative speech, metaphor, Relevance Theory, simile

\section{Introduction}

Aristotle was the first to propose that metaphors are implicit similes in his works Poetics and the Rhetoric. The early theories state that simile and metaphor understandings are both comparisons differing in the explicitness of the indicators of resemblance. Thus, the experimental studies following these accounts use similes to test metaphor interpretation in children. However, according to the Relevance Theory(RT), metaphors are interpreted as categorization statements, whereas similes are interpreted as comparisons. Children should be able to construct an ad hoc concept to understand a categorization statement. Similes should not be used as materials to test children's metaphor understanding ability since they are easier to understand.

By reviewing and reinterpreting the early and developmental empirical studies, this study analyses whether these empirical studies tested "real metaphor" interpretation in children. We propose that if the empirical findings under both theoretical frameworks demonstrate that children's performance in simile understanding is different from and better than that in metaphor comprehension, then RT will be supported. If comparison interpretation indeed happens at an earlier age in children, it benefits to construct the ad hoc concept that metaphor interpretation requires. Thus, this study attempts to reconcile the two theories in this perspective. If the hypotheses establish, this study supports RT that children interpret similes as comparisons while metaphors as categorization statements, which enhances our knowledge of children's language development linguistically.

\section{Models of Simile and Metaphor Comprehension in Adults}

Simile and metaphor comprehension theories mainly include early comparison theory following Aristotle (Miller, 1974, 1976, 1988), recent comparison theory by Ortony $(1978,1979,1993)$, the interaction theory (Black, 1962; Richard, 1965), the categorization theory (Glucksburg, 1990, 1998, 2006, 2011; Carston, 2002; Sperber \& Willson, 2008), and other theories (see Grice, 1975, 1978; Lakoff, 1986; Searle, 1969). Terminology in these theories varies accordingly. This study classifies the related theories as two theoretical models: the comparison view and the categorization view. We review metaphor interpretation in adults under these two models in this part. 


\subsection{The Comparison View of Metaphor}

"simile is also a metaphor. The difference is but slight" (Aristotle, in Glucksberg and Haught, 2006). In Aristotle's view, metaphor is almost equivalent to simile based on analogy, except that simile requires the explicit form "like/as" (Ortony, 1993).

The comprehension model of vehicles in comparisons covers three stages: deriving the literal meaning; assessing the interpretability of that meaning; if the literal meaning does not work, deriving non-literal meaning (Glucksberg and Keysar, 1990). Hereafter, the term "vehicle" refers to the carrier of the figurative meaning in figurative speech. According to this model, Tversky constructs the contrast model (1977), and Ortony develops the matching model (1978), which are the most outstanding models under comparison theory.

In the form of " $a$ is like $b$ " in Tversky's model:

$$
s(a, b)=\theta f(A \cap B)-\alpha f(A-B)-\beta f(B-A)
$$

$s(a, b)$ stands for the similarity between the two terms $a$ and $b, \theta$ the weight assigned to the features of both $a$ and $b, \alpha$ the weight of features distinct to $a, \beta$ the weight of features distinct to $b$ (Ortony, 1979; Glucksberg \& Keysar, 1990). For instance:

(1) The sun is like an egg yolk.

Term $a$ is "the sun", $b$ "an egg yolk". Set A contains features of the sun, such as the largest planet, centre of the universe, bright, hot, orange, and round. The features of egg yolk-set B-contain round, orange, the centre of the egg, food and so on. The intersection $f(A \cap B)$ includes shared properties such as being round, central, orange, and so on. The salience of attributes to $a$, namely the features distinctive to a, is represented by $f(A-B)$. The salience of attributes to $b$, i.e. food, is represented by $f(B-A)$. If it is a comparison, then $f(A-B)$ and $f(B-A)$ are irrelevant. Then we assign $\theta=1, \alpha=\beta=0$ and get $s(a, b)=f(A \cap B)$, in which the intersection of sets A and B represents the two terms' similarity. However, Tversky's model is not flawless, because mathematically if $\alpha=\beta=0$, then $s(a, b)=s(b$, a), which is not true in most language cases. For example,

(2) Egg yolk is like the sun.

(2) is not equivalent to (1) because (1) reveals more features of "an egg yolk" than those of "the sun". When we consider the similarity of " $a$ is like $b$ ", we are judging the similarity of $b$ to $a$, resulting in more focus on the subject than the object: $\alpha>\beta$ (Glucksberg \& Keysar, 1990). Applied in the formula, $s(a, b)>s(b, a)$. This asymmetry or non-reversibility in metaphorical comparison is not well explained in Tversky's theory.

Ortony (1979) reject Tversky's assumption that the salience of an attribute is independent of the object and explains how metaphoricity embodies in his modification of Tversky's model. He proposes "the salience of the intersection of $A$ and $B$ is dependent on the salience values of matching elements in $B$, rather than on some function of the values in both $A$ and $B$ or of their values in A alone." (ibid.) He claims that there are two factors affecting metaphoricity: salience imbalance and attribute inequality. Salience imbalance means "context influences and determines the particular aspects of word meanings that are salient on any particular occasion" (Ortony, 1990). Attribute inequality requires that the domains of the two terms are incongruent. The re-constructed formulation by Ortony is:

$$
S(a, b)=\theta f^{B}(A \cap B)-\alpha f^{A}(A-B)-\beta f^{B}(B-A)
$$

where $f^{\mathrm{A}}$ is the salience of properties in term a, $f^{\mathrm{B}}$ in $\mathrm{b}$. The measure of similarity remains the same as Tversky's model. For instance:

(3) Billboards are like placards. (Ortony 1979)

(4) Billboards are like warts. (ibid.)

In (3), "billboards" $(a)$ and "placards" $(b)$ share high salience of attributes: High A/High B, forming a literal comparison. In (4), $b$ carries some of its high-salient attributes that are less salient to $a$ (e.g. warts are ugly): High B/Low A, forming a metaphorical comparison. Any other Low B/Low A or Low B/High A would result in anomalous comparisons:

(5) Billboards are like pears. (Low B/Low A)

(6) Sleeping pills are like sermons. (Low B/High A)

The theory works well so far. However, consider this example:

(7) Billy is like a block of ice.

Where Billy is a proper name, so set A is empty. There is no way to determine how high or low the salience is. 
Ortony noticed this severe problem and referred to it as "property introduction" since the properties of the topic could only be mentally represented until the metaphor/simile is interpreted (Glucksburg, 1990). Thus, we have to abandon the matching model whenever a new subject is introduced to the listeners (Ortony, 1979). Furthermore, whether metaphor interpretation differs from simile interpretation is not illustrated by both models.

Miller (1988) explains this by sharing some of Ortony's views. For instance:

(8) My love is a red, red rose.

(9) Billy is a block of ice.

(10) My lawyer is a shark.

(8) is understandable by paraphrasing as "My love is like a red, red rose". (9) and (10) denote the same interpretation as its corresponding simile respectively. Miller claims that readers must distinguish "true in fact" from "true in the model" (Miller 1974). If the speaker says $a$ is $b$ when the readers know that $a$ is not $b$, the reader must imagine a world where $a$ is $b$. This world is "true in the model" (ibid.). As for metaphor interpretation, similarities or resemblances enable us to understand why the speaker says $a$ is $b$ where $a$ is not $b$. Thus, $a$ is like $b$ makes $a$ is $b$ "true in fact".

Miller constructs his model of nominal metaphor using the notation of functions and arguments:

$$
B E(x, y) \rightarrow(B F)(B G)\{\operatorname{SIM}[F(x), G(y)]\}
$$

where $B E$ is for the verb "to be", SIM for similarity, $F(x)$ and $G(y)$ for some properties of $x$ and $y$ respectively. A metaphor " $x$ is $y$ " is interpreted by reconstructing a corresponding comparison where some properties of $x$ are like some properties of $y$. For example (8) BE (my love, red rose) $\rightarrow(B F)(B G)\{S I M[F$ (my love), G(red rose)]\} is paraphrased as some properties of my love are like some properties of the red rose. The properties include the influences that love and red roses share: sweetness, passion, and warmness.

In Miller's view, the corresponding similes for metaphors are interpreted as literal statements, which are rejected by Ortony (Ortony, 1979, 1993). Ortony argues that similes are non-literal comparisons, so transferring a metaphor into a simile cannot explain the metaphoricity in the comparison. For instance, in (8), "My love" cannot be like "red rose" at all since it is metaphorically like it. Thus, the problem does not lie in the surface structures of comparison statements but lies in the explanation of non-literal similarities of similes or analogies. Ortony emphasises that simile is also metaphorical use of language.

Although Ortony's comparison view is not identical to the traditional comparison view insisting similes are literal comparisons, comparison theorists reached the agreement that metaphors should be paraphrased to corresponding similes or analogies. Metaphors are the covert or implicit comparison statements without the linguistic forms "like/as".

\subsection{The Categorization View of Metaphor}

The idea that metaphor is one type of categorization statements is primarily put forward by interaction theory (see Black, 1962; Richard 1965), later modified and further developed by Glucksburg with class-inclusion theory (1990).

Initially, metaphors were treated as absurd statements because they "say one thing and mean another" (Black, 1962). Black argues that the producer said what he intends to mean, which could be interpretable in a specific context not from the lexicon. He writes that a metaphor has a "primary" subject, the subject in syntax and a "secondary" subject, the object in syntax. The secondary subject named "implicative complex" was marked by the metaphorically used word. The metaphor was realised by "projection": projecting the relevant properties in the implicative complex to the primary subject. The process of projection is "interaction": firstly, the hearer selects the properties of the secondary subject according to the presence of the primary subject; secondly, the hearer constructs a one-to-one parallel implicative complex that fits to the primary subject; last, parallel changes in turns happen to the secondary subject (ibid.). For instance,

(10) The Internet is a goldmine.

The implicative complex will be built as follows: $(\mathrm{G}=\mathrm{Goldmine})$

(G1) A "goldmine" is an exploring place;

(G2) which hides gold;

(G3) that is valuable and deserves digging out. 
The corresponding interpretations for the primary subject are: (I=Internet)

(I1) The "Internet" is a visual reality;

(I2) which provides information;

(I3) that is useful (valuable? profitable?) and worth finding out.

The relation between (G1-3) and (I1-3) is described as a one-to-one mapping in an isomorphic structure (ibid.). The interaction between the primary (I) and secondary (G) subjects makes the metaphor meaningful. In the view of Black, metaphor cannot be replaced by its corresponding simile, because any paraphrase of a metaphor will weaken a relation of inclusion instead of similarity.

In 1990, Glucksberg and Keysar further argued that metaphors are class-inclusion categories (Glucksberg \& Keysar, 1990). It takes on different grouping strategies from conventional categories: "to use the name of a prototypical noun to refer to a super-ordinary category that does not have a conventional name" (ibid.). The form " $x$ is a $y$ " should be understood as $x$ is a member of the category in which $y$ is a prototype. During this process, the literal meaning of the vehicle is actively suppressed because of its irrelevance (Glucksberg, 1998; Glucksberg et al., 2011).

(11) My job is a jail.

Conventionally, "jail" denotes a kind of legal sentence with members such as executions and fines; a member of punishment along with scolding and spankings. (Glucksberg \& Keysar 1990) Unconventionally, jail can be a member of a situation which involves feelings like struggling, depressed, and stressful. The dimension of "job" determines the irrelevancy of conventional meaning. As a result, "my job" becomes a member of "a jail" with its original meaning.

More recently, Glucksberg and Haught propose that some metaphors and their corresponding similes yield different interpretations, so metaphors must be understood as class-inclusion statements and similes must be interpreted as comparison statements (Glucksberg \& Haught, 2006).

Relevance Theory supposes that metaphor interpretation is achieved as literal, loose and hyperbolic interpretations (Sperber \& Wilson, 2008). Thus, to comprehend a metaphor is to interpret a loose usage of language, requiring the listener to decode the encoded speaker's meanings. The process is to construct the ad hoc concept constructed by the hearer according to the context when comprehending a figurative utterance (Carston, 2002). In other words, "to produce a metaphor is to assert [some part of] the metaphor's content" (Wearing 2010).

Usually, there are two ways of constructing the concept: narrowing and broadening (or loosening) (Carston, 2002). As for narrowing, the ad hoc concept denotes a narrower meaning than the original meaning. For example, "The birds wheeled above the waves" where the ad hoc concept BIRDS* denotes seabirds that exclude robins, owls, sparrows and the like (ibid.). As for broadening, the ad hoc concept denotes a broader concept than the linguistic meaning. For instance, one says "the steak is raw" meaning that the steak is less cooked than one wishes. The ad hoc concept RAW* denotes a broader concept since the steak is not raw but an approximation to raw for the eater. Sometimes, narrowing and broadening (or loosening) overlap in different respects in one utterance (Carston, 2002).

Nevertheless, what cues do we use to construct the ad hoc concept? According to the Relevance Theory, at least one of the three kinds of information must be available: "logical content, encyclopaedic or general knowledge, and lexical properties." (ibid.) When a concept is introduced, all properties from the encyclopaedic knowledge are activated. According to the context, a ranking is formed based on the degree of activation as well as relevance. For instance:

(12) a. Tom: It's my little brother's birthday tomorrow. It would be a good idea to organize a show for him.

Rose: Oh, Jack is a magician. Let's go and ask him.

b. Jenny: You look amazing!

Rose: My plastic surgeon is a magician!

In (12) a., we derive the following properties from the word MAGICIAN:

(1). playing magic tricks to amuse others.

(2). wearing colourful or shining costumes

(3). making sudden and surprising changes 
(4). being able to perform magic

(5). being experienced and skilful in his expertise

A range of these properties can be activated from the concept of MAGICIAN, but only some of them are selected and ranked highly based on different contexts. In (12) a., Tom is expecting that Rose will provide some suggestions about giving shows on his brother's birthday. Thus, the explicit content of Rose's utterance is judged directly relevant to (1)-(3) listed above. The ad hoc concept MAGICIAN* is the same as the literal meaning of MAGICIAN. In (12) b., Jenny is expecting Rose to give some reasons or explanations to respond to her complimentary comment on Rose's change in appearance. The properties are adjusted in another order until Jenny's expectation and Rose's implication are satisfied. So, properties (3). and (5). are activated earlier and ranked higher. "My plastic surgeon is a magician" cannot be interpreted until Rose builds up the ad hoc concept MAGICIAN**, someone who is skilful in making sudden and surprising changes to others.

Although (12) a. is a literal interpretation and (12) b. is a metaphorical interpretation, their interpreting process is the same. MAGICIAN** is a loosening use of language as the literal meaning of "magician" has been broadened to refer to a category of people who are not real magicians. To some extent, narrowing also occurs because only some properties of the magician are taken from MAGICIAN. So, Relevance Theory suggests that metaphor comprehension employs the same mechanism as other literal interpretation, namely, the construction of the ad hoc concept. The product of the ad hoc concept is treating metaphor as categorization assertions, in accordance with the proposal by Glucksberg (2011).

Now the question comes to how simile is interpreted on RT account? The explicature of a metaphor lies in the ad hoc concept, whereas the explicature of a simile lies in its lexically encoded concept: (Carston \& Wearing, 2011).

(13) a. My plastic surgeon is a magician**.

b. My plastic surgeon is like a magician.

In (13) a, the surgeon belongs to the category of MAGICIAN**. However, in (13) b, a surgeon can only be like a magician instead of like MAGICIAN**, since one thing cannot be like the category it belongs to. For example, we can say "a banana is like an apple", but we cannot say "a banana is like a fruit". The vehicles in metaphor and simile have different referents: metaphor vehicle refers to an abstract category; simile vehicle refers to the literal concept (ibid.). Metaphor interpretation requires suppressing irrelevant logical information and selecting relevant encyclopaedic information to build up a new abstract category, whereas simile interpretation requires comparing the properties of two literal concepts. Thus, simile comprehension is believed to be easier than metaphor understanding in RT.

In summary, the comparison theory treats metaphor and simile as comparable types of figurative comparisons. Metaphor is interpreted based on simile because metaphors are implicit similes. However, the categorization theory regards that metaphors are categorization statements requiring the construction of an ad hoc concept according to the particular context. Similes are comparison statements between two literal concepts. In this perspective, Relevance Theory is in accordance with the categorization theory.

\section{Implications for Developmental Research in Children}

From the two theoretical frameworks discussed in 2., the developmental debate over children's metaphorical abilities has two directions. For comparison theories that regard similes and metaphors as the same type of figurative expression, developmental studies showing simile understanding are evidence that young children can understand metaphors. However, for the categorization account (also RT), only metaphors reveal metaphor understanding. In other words, evidence of simile understanding is not evidence of metaphorical abilities in early childhood.

Metaphor comprehension and production should both be taken into consideration. Under either framework, producing real metaphors requires one to distinguish the difference of the topic and vehicle categories, children must be able to consciously violate the established categories to produce a true metaphor (Billow, 1981). This ability is rooted in cognitive development.

Typically, the cognition of a human develops through four stages: sensorimotor stage (from birth to the acquisition of language), preoperational stage (from 2 to 7 years old), concrete stage (from 7 to 11 years old) and formal operational stage (older than 11 years) (Piaget, 1955, 1966). Only in the third and fourth stages can children use logic appropriately. At the formal operational stage, children can interpret abstract concepts (ibid.). Inhelder and Piaget (1969) proposed how cognitive development works in classifications. At the age of 7-11 years old, children can understand metaphors that are based on similarity. According to this theory, children's 
competence in comprehending metaphor fully develops at least by the age of 11 . The "child metaphor" is not considered as a real or true metaphor but as some sort of error or overextensions by applying one known name to another unknown object.

However, it is argued that classifying all "child metaphors" as overextensions is not correct. For instance, an 18-month-old child called a toy car "snake", when it twisted around his mother's arm; a 2-year-old child called his father a "kiwi" when his father's hairs started growing back after shaving (Pouscoulous, 2011). Carlson's 2-year-old son said "cup swimming" while he pushed it in the water (Vosniadous, 1987). Other naturalistic investigations taken by Grindstaff (1975), Horne (1966), and M. Pollio \& H. Pollio (1974) also provide evidence for early production of metaphors in children. Other evidence showing children's ability to rename the objects and produce real metaphors are also demonstrated. (Gentner, 1977; Vosniadou \& Ortony, 1983).

Our question: are these productions of metaphors "real metaphors"? As is known in language acquisition, comprehension takes place earlier than production. If the early metaphor-like utterances are considered as real metaphors production, we infer that children's metaphor comprehension should be at an even earlier age. Can we find evidence showing children younger than 2-year-old has the ability to comprehend a metaphor?

Early studies, especially from 1970 to 1978, yield confusing and conflicting results on metaphorical comprehension. Some studies indicate that children as young as three years old have some rudimental metaphor comprehension competence like understanding physical meanings of terms (e.g. Gardner, 1974; Gentner, 1977). Whereas, other studies demonstrate that children at the age of 10-12 fail to paraphrase or explain metaphors, especially those involving psychological-physical transfers (see Ash \& Nerlove, 1960; Cometa \& Eson, 1978). No findings show that any child younger than 2-year-old understands metaphors. Thus, we question the findings that show children's early production of metaphor. The failure of the performance in the test is either attributed to children's poor comprehension ability of metaphors or the poor testing methodology.

Two explanations of children's poor comprehending ability on metaphors are the literal stage hypothesis and the cross-conceptual category difficulty (Vosniadou, 1987). For the literal stage hypothesis, the literal meaning of metaphorical statements is given priority in understanding the metaphor (see Ash \& Nerlove, 1960; Winner, Rosenstiel, \& Gardner, 1976). In other words, children interpret metaphors literally and fail to understand them. The other explanation suggests that children's inability is due to the lack of conceptual knowledge about identifying similarity between different categories or classifications. This theory accords with the Piagetian theory, taking cognitive development as the basis of metaphor interpretation. Billow (1975) was the first to combine the Piagetian theory with metaphor interpretation (Vosniadou, 1987). Cometa and Eson (1978) applied the same idea in their experiments. This explanation is in parallel with the categorization theory in the way that children cannot fully understand metaphors at an early age before he fully develops the strategies for categorization.

On the other hand, studies point out the improper methodology applied in the experiments of testing children's metaphor comprehension ability caused unconvincing and inconsistent findings: lack of context, confounding of metacognitive demands and complexity of linguistic input (Vosniadou, 1987). The degree of complexity of linguistic input affects children's performance. Vosniadou (1987) summarised different aspects of linguistic input that affects metaphorical interpretations in children. Similes, analogies, and metaphors are all metaphorical expressions, among which similes and analogies are more accessible for children. (Ortony, 1979; Reynolds \& Ortony, 1980 and Vosniadou et al., 1984)

Although children's performances are improved with some modifications to testing methods, it is still not convincible for RT that children's real metaphor comprehension ability is tested correctly as these experiments are still using similes to guide children or to explain metaphors. These modified experiments include experiments using multiple-choice and enactment tasks (see Ortony et al., 1978; Winner, Engel, \& Gardner, 1980; Keil et al., 1986; Vosniadou \& Ortony, 1986). Some studies use context-based tests (Reynolds \& Ortony, 1980), multiple-choice tests (e.g. Nippold, Leonard, \& Kail, 1984; Winner et al., 1980) or choosing-picture task (see Epstain \& Gamlin, 1994).

To conclude, early studies show that children certainly have some metaphorical ability at an early age, yet it is not clear whether it is simile or metaphor interpretation since "real" metaphor comprehension is not tested. If a metaphor is not an implicit form of the corresponding simile, but a categorization statement as RT insists, all the findings from the studies following the comparison frame are not interpreted on the right track in RT. However, we can reinterpret these empirical data along with the developmental studies under a different account to see whether RT will be supported. If the tests of "real metaphor" prove that metaphor interpretation develops at the same pace with children's categorization knowledge and occurs later than simile interpretation, then simile 
interpretation is easier than metaphor interpretation for children, thus supporting RT.

\section{Re-Interpret Experimental Studies with Children from a Relevance-Theoretical Perspective}

Many surveys show that children should obtain a certain degree of metaphor comprehension ability to fulfil the education requirements: comprehension and production of metaphors (see Arter, 1977; Sweet, 1974; M. Pollio \& H. Pollio, 1974; Horne, 1966). Researches on children's interpretation of metaphors become increasingly significant. This section aims to re-interpret the early empirical findings to see whether such findings are also useful and interpretable ones to review and discuss.

\subsection{Studies Using Similes and Analogies}

Gentner (1977) did an experiment with children aged 4 to 7 and adults, using analogical tasks to test the metaphorical ability. In Experiment 1, children were asked to map a human body (as one domain) to a tree or a mountain (as the other domain) in pictures. In the Orientation task, the presentation of a tree is rotated as upside-down, up-right or horizontal. In the Local-feature task, some misleading human-body parts were added to the mountains. The subjects were asked, "if the mountain had a knee, where would it be?" (ibid.) Children should point out the correct positions. For instance, the eyes of the mountain must be above the mouth. The results showed that, in the Orientation task, all groups performed well, and children as young as four years old did as well as adults; in Local-feature task, children did even better than adults.

Gentner suggested that young children possess the ability to understand similarities between different domains, but it should be seen as an analogical ability rather than metaphor comprehension ability because children did not show a deliberate violation of domains in these experiments (Gentner 1977).

Following Ortony's theory of domain incongruence and salience imbalance (1979), Vosniadou \& Ortony (1983) designed an experiment with a comparison task and a categorization task. Children were asked to complete sentences in the form "A is like B or C", choosing one word from some pairs of words. The word pairs were in different linguistic forms: metaphorical/literal pair (M/L), literal/anomalous pair (L/A) and metaphorical/anomalous pair (M/A). For example, for a sentence "A river is like a _,", children should choose words from snake/lake (M/L), lake/cat (L/A), and snake/cat (M/A) (Vosniadou \& Ortony, 1983).

Correspondingly, a categorization task was performed to test whether children could distinguish different conventional categories. Children were asked whether "A is the same kind of thing as B or C". For example, "Is sugar the same kind of thing as honey/snow/road?"

The first significant finding was that children as young as three years old could reject anomalous expressions (e.g., "a river is like a cat") in both tasks. The second finding was that children of all age groups showed no preference for metaphor or literal response in $\mathrm{M} / \mathrm{L}$ comparison task. The third finding showed that as children age, they choose more correct words in the categorization task. Three-year-olds failed to distinguish categories, but 4-year-olds and older performed well. For instance, they know "a leg is the same kind of thing as an arm because they are part of the body" (Vosniadou \& Ortony, 1983). The conclusion is that by the age of 4, children obtained some metaphorical ability.

We should notice that this study uses similes to test children's metaphorical abilities, which, according to the RT account, is more straightforward than real metaphor comprehension. However, we do not deny that identifying similarity should be "one important prerequisite for metaphor comprehension and production" (ibid.). We propose that similarity understanding plays an essential part in the process of ad hoc concept construction. Comprehending similarity directly influences the selection and ranking of relevant properties to form the set of properties in the ad hoc concept, since the interaction between the topic and vehicle determines the degree of relevance of the properties.

For instance, without any context, the word "snake" denotes lots of properties: limbless scaly elongated reptile, treacherousness, things with fangs, deadly and dangerous features and the like. However, when we talk about a metaphor "a river is a snake", we somehow form the ad hoc concept of SNAKE* where all types of winding and twisting things are included in this category. It is in this "somehow" process that similarity works. Since the "snake" is regarded as the prototype of SNAKE*, it must take on the most salient property in the SNAKE* concept. Thus, we suppose that although metaphor is a categorization statement, the comprehension process should consider similarity understanding between the two items.

Another work by Epstein and Gamlin in 1994 aims to test young children's comprehension of simple and complex metaphors also adopting similes as the linguistic testing form. Children of 3-5 years old participated. Twenty pairs of metaphorically related objects were presented in pictures and corresponding word forms. Some of them rely on explicit (or apparent) similarity, for example, eyes are like buttons based on roundness. The 
others depend on implicit similarity; for instance, horses are like bicycles based on riding function. Children should choose one object that is like the pointed one among the three candidate objects or events in picture task and choose one that likes the given topic in word task. For instance, pictures of "zipping up a zipper", "sealing an envelope" and "unhappy boy" are presented, and children are allowed to choose a similar one to "zipping up a zipper"; correspondingly, children were asked, "zipping up a zipper is like ?" In both tasks, children were required to explain the reasons for choices.

Results showed that some children as young as three years old could explain the relations of implicitly related objects. For example, children responded that "zipping up a zipper" was like sealing an envelope, since "it makes things come together" (Eptain \& Gamlin 1994). Another finding was that children showed greater competence in a picture task than a word task, demonstrating that task demand influences the performance. The authors concluded that young children have established "metaphoric linkages" more than perceptual (explicit) similarities. Here, we notice that the third candidate choice, "unhappy boy", is not an event at all. As long as they can distinguish events from objects, they can make a correct link. We checked all the events candidates; the anomalous choices are all objects instead of events, resulting in much easier selection for children. Moreover, by asking "which is like A?", there is no metaphorical language used at all. Thus, we are unconvinced by the conclusion that young children by the age of 3 can interpret metaphor.

Thus, our interpretation is that children just show fundamental ability in similarity comparisons, which is useful and vital in forming ad hoc concepts under the RT account, especially during the ranking process. This ability will develop with the accumulation of the conceptual knowledge of the world and the experience of life.

\subsection{Studies Distinguishing Similes and Metaphors}

Based on comparison theory, Reynolds \& Ortony (1980) did an experiment with children aged from 7 to 12 . The experimenters read stories and let the participants select the sentences that best completed the stories. Altogether, three sets of sentences were given: Literal-target, Simile-target and Metaphor-target set. In each set, four alternatives were given with only one correct choice. Two findings were significant: first, the number of correct answers in the Simile-target set was more than that in the corresponding Metaphor-target set; second, the general performance improved with the increase of age.

Taking the task material of how a broken-down horse was discarded by his owner as an example, making the target choice requires children to understand "The broken-down horse is like a worn-out shoe" or "The broken-down horse is a worn-out shoe". For the latter, children have to infer that WORN-OUT SHOE* refers to a class of things that are too old to be used and have to be discarded. The literal meaning of the worn-out shoe is suppressed to form a superior and broadening class of old and abandoned things. Thus, the broken-down horse becomes a member of the WORN-OUT SHOE*. However, for the simile, children only need to know the two things are too old to be used, where no suppression or construction of concepts is required. So, the findings support RT that simile comprehension is more accessible than that of metaphor.

Seidenberg and Bernstein (1986) tested the comprehension of similes and metaphors with learning-disabled (LD) and non- learning-disabled (non-LD) children under the same research paradigm as Reynolds and Ortony (1980). The result was that LD children understood similes significantly better than metaphors, in contrast to the non-LD children group. Seidenberg and Bernstein concluded that it was due to the "explicitness of the comparison signalled by the grammatical surface structure of the simile" (1986).

To account for the poor performance by LD children in metaphor conditions, some studies indicated that learning disabled children might understand the figurative languages literally (Wiig \& Semel, 1984). Based on the Relevance Theory, which treats similes as literal interpretation and metaphors as categorization statements, learning disabled children's better performance of simile comprehension should be attributed to cognitive development rather than just syntactical differences. They show little understanding of metaphors because they interpreted them literally. Since the metaphor vehicle was only interpreted literally, children might just identify the similarities between the two terms and cannot classify two similar things into new unconventional and abstract categories.

In summary, most studies that distinguish simile and metaphor comprehension demonstrate that simile interpretation is easier than metaphor (for further references see Ortony, 1979; Vosniadou et al., 1984). This result supports RT account because metaphor comprehension requires the construction of ad hoc concept, which involves selection, ranking and suppression of properties. However, in simile comprehension, only the selection of similar properties is taken into consideration. Simile comprehension is thus simpler than metaphor comprehension. 


\subsection{Studies Using Metaphors}

Ash and Nerlove (1960) and Gardner (1974) tested children's ability to use dual-function words in different contexts correctly. Dual-function words are words that can be applied literally in the physical domain and non-literally in the psychological domains. 3- to 12-year-olds were asked whether such dual-function words like "hard", "sweet", "cold" could be used to describe people. The results showed that children do not accept the non-literal meaning until 11 or 12 years old.

Gardner developed Ash and Nerlove's paradigm in the experiment with children aged three and a half to eleven and a half years old. The testing materials were polar adjective pairs: "light/dark, happy/sad, loud/quiet, hard/soft and warm/cold", falling into five concrete domains: colours, facial expressions, pitches, tactile presentations and verbal-kinaesthetic presentations (Gardner, 1974). Participants were required to map polar adjective pairs from one domain to another. For instance, "Which colour is cold, blue or red?" The result was that older children gave more correct answers than the younger ones. In addition, there was an order of the difficulty when different adjectives are assigned metaphorically to different domains: the verbal-kinesthetic domain (warm/cold) was the easiest, tactile (hard/soft) the intermediate, auditory (loud/quiet) the hardest (ibid.).

The non-literal usage of words is, in fact, testing metaphor interpretation in the psychological domain. That children deny these metaphor usages until 11 or 12 supports the RT account because metaphors involving abstract and psychological vehicles are relatively harder to interpret, thus, later developed with the maturity of children's cognitive knowledge.

We suggest that once the children understand the interactions of the two domains, they can appreciate corresponding metaphors by selecting the most salient features to form an inclusive class. For example, children at first distinguish that "blue" and "cold" are from different domains; then, the encyclopaedic properties of BLUE and COLD are activated. Since BLUE will be a member of the ad hoc concept COLD*, BLUE and COLD must have something in common that put them together into COLD*, which we believe involves similarity comprehension and logic inference. After searching and ranking the most salient properties, the category COLD* is formed as the psychological feeling of calm, indifference, sadness or lack of emotion. The higher request for cognitive development for setting up an abstract concept adds difficulty in metaphor comprehension.

Other studies with either a result showing a developmental trend with the increase of age or a result of domain comprehension differences support that adequate conceptual knowledge is the prerequisite of good metaphor comprehension (for further references, see Ash \& Nerlove, 1960; Billow, 1975; Gardner, Winner et al., 1976; Vosniadou \& Ortony, 1983; Evans \& Gamble, 1988; Pearson, 1990; Thomas et al., 2010).

Two studies by Cometa \& Eson (1978) and Keil (1986) applying Piagetian theory in metaphor comprehension will present us with more clear evidence for the necessity of cognitive development in metaphor comprehension. According to Piagetian theory, children's ability to comprehend metaphor is based on the "operationalization of intersectional classification" (Cometa \& Eson, 1978). That is, the meanings of two terms (or symbols) in metaphor are not fixed but vary depending on the operative structures constructed individually.

In Cometa and Eson's experiments, children were grouped into pre-operational (P), concrete operational (C), intersectional (I) and formal operational (F) group (Cometa \& Eson, 1978). After completing the tasks of Piagetian experiments, children took part in the corresponding metaphor interpretation task. For example, by listening to the sentence "when the wind blew, the leaves began to dance", the children were asked, "what does it mean to say that leaves dance?" (ibid.)

The results indicated that the preoperational group (at 2 to 7 years old) could not explain these metaphors. The metaphor comprehension ability appears after concrete operations (at 7 to 11 years old). The different responses from Group I and Group C demonstrated it. Laura, aged 7 1/2 in C group, answered the question as the leaves "move all around and go back and forth" but "leaves do not really dance they don't have feet!", showing she could not explain why we use "dance" here. Whereas Patrick, aged 10 1/2, Group I member, explained: "people shake back and forth when they dance, so it is just like the leaves do when the wind pushes them" (ibid.). Thus, on the foundation of Piagetian stages, children's comprehension of metaphor begins to develop only after the concrete stage (at least seven years old) and further develops in the intersectional stage during 9-11 (ibid.).

Similarly, Keil claimed that the two terms in metaphor should be seen as an interaction of semantic fields (Vosiniadou, 1987). Thus, if children can apply one member of a domain into figurative use, then other members of the same domains will be applied as well. Children of 5/7, 8/2 and 9/5 were asked to explain the meaning of metaphorical terms from different categories: car with animate terms, wind with human vocalizations, eating 
terms with a book, and so on. For example, "The car was sick"; "the wind whispered"; "she was a silky person".

The result showed that metaphors among animate/inanimate domains are earlier and easier to understand. For instance, kindergartners explained "a tired car sleep" as "it stops running". Nevertheless, in abstract domains, interpretation ability on metaphor develops more slowly with more difficulties, say, eating terms with people and taste/texture/weather terms with person. Also, children's comprehension of metaphors emerges "in a unified, all-or-none manner" within each conceptual domain (Keil, 1986).

These studies present us with a developmental trend of metaphor interpretation ability with the increase of age and expansion of cognitive knowledge. Under RT frame, the vehicle should not be interpreted literally, because it denotes all encyclopaedic and logic entries just as inclusion statements. We propose that by recognizing the similarity between the two domains, the ad hoc concept is constructed by selecting and ranking the properties according to the degree of relevance. Cognitive knowledge is necessary for activating the encyclopaedic and logic properties as well as forming the ad hoc concept. With the increase of age and knowledge, metaphor comprehension will be easier and more mature.

\section{Discussions}

Through the re-interpretation of the empirical studies regarding the interpretation of simile and metaphor in children, we conclude these findings generally support our speculations.

Firstly, the simile-based or analogy-based tests of metaphorical comprehension abilities proved that children as young as three years old have some rudimentary ability in recognizing similarities in comparisons, and this ability develops with the increase of age. Based on RT, we propose our idea that even though metaphor comprehension is fundamentally different from simile comprehension, similarity recognition is an essential strategy for the construction of the ad hoc concept. The similarity between the topic and the vehicle in a specific context determines the salience of encyclopaedic properties. The vehicle functions as a prototype in the newly built ad hoc concept. However, only noticing the similarity is far from succeeding in understanding metaphor, because without the help of enough cognitive knowledge, some abstract concepts will not be understood and the measurement of relevance will not interact in the construction process of the ad hoc concept.

Secondly, empirical researches using both simile and metaphor as test material shows that simile understanding is more accessible than metaphor understanding. In comparison theory, it is believed that the explicitness of "like/as" simplifies metaphorical comprehension, as the equivalence of metaphoricity in similes and metaphors. However, RT argues that the metaphoricity in similes and metaphors are not the same. Interpreting simile only requires finding out the similarities, whereas comprehending metaphors requires us to activate all properties of the terms, selecting and ranking them to construct a new category. Thus, a higher level of world knowledge and reasoning ability is required. Despite disagreement on the explanation of why simile comprehension is easier, the experiment findings support both comparison theory and RT.

Thirdly, the real metaphor tests and categorization tests indicate that children's comprehension of metaphor starts from an early age but fully develops from 9 to 11, in accordance with the logic operation development in Piagetian theory. These findings support both theories: comparison theory and RT.

\section{Conclusion}

Our re-interpretation inspires us to think of the comparison theory and categorization theory as a whole, which is not indicated by the standard RT. We argue that similarity should be considered as an essential element for the construction of the ad hoc concept in RT. The ability of simile comprehension facilitates the building of a narrowing or broadening use of language. Full-grown comprehension of metaphor requires the ability to recognize similarity, selecting salient properties, ranking by relevance, and constructing superior classification with the help of abstract cognitive knowledge.

The present work has reviewed the theoretical frameworks on adult comprehension of simile and metaphor under comparison theory and Relevance Theory. By reviewing and re-interpreting the empirical findings from 1960 to 1990 , we suggest that the comparison theory should not be treated separately from the recent theory, because the findings in experiments apply to both theories in different perspectives. 


\section{References}

Arter, J. L. (1977). The effects of metaphor on reading comprehension (Doctoral dissertation, ProQuest Information \& Learning).

Ash, S., \& Nerlove, H. (1960). The development of double function terms in children: An exploratory study. Perspectives in psychological theory. New York: International University Press, 1(960), 47-60.

Black, M. (1962). Models and archetypes. Models and Metaphors: Studies in Language and Philosophy (Ithaca, New York: Cornell University Press, 1962) p, 22, 664-677.

Billow, R. M. (1975). A cognitive developmental study of metaphor comprehension. Developmental Psychology, 11(4), 415. https://doi.org/10.1037/h0076668

Billow, R. M. (1981). Observing spontaneous metaphor in children. Journal of Experimental Child Psychology, 31(3), 430-445. https://doi.org/10.1016/0022-0965(81)90028-X

Carston, R. (2002). Metaphor, ad hoc concepts and word meaning-more questions than answers. University College London, working Papers in Linguistics, 14, 83-105.

Carston, R., \& Wearing, C. (2011). Metaphor, hyperbole and simile: A pragmatic approach. Language and Cognition, 3(2), 283-312. https://doi.org/10.1515/langcog.2011.010

Cometa, M. S., \& Eson, M. E. (1978). Logical operations and metaphor interpretation: A Piagetian model. Child Development, 649-659. https://doi.org/10.2307/1128232

Epstein, R. L., \& Gamlin, P. J. (1994). Young children's comprehension of simple and complex metaphors presented in pictures and words. Metaphor and Symbol, 9(3), 179-191. https://doi.org/10.1207/s15327868ms0903_2

Evans, M. A., \& Gamble, D. L. (1988). Attribute saliency and metaphor interpretation in school-age children. Journal of Child Language, 15(2), 435-449. https://doi.org/10.1017/S0305000900012447

Horne, N. H. (1966). A study of the use of figurative language by sixth grade children (Doctoral dissertation, University of Georgia, 1966). Dissertation Abstracts International, 27, 67-3.

Gardner, H. (1974). Metaphors and modalities: How children project polar adjectives onto diverse domains. Child Development, 84-91. https://doi.org/10.2307/1127753

Gentner, D. (1977). If a tree had a knee, where would it be? Children's performance on simple spatial metaphors. Papers and Reports on Child Language Development, 13, 157-164.

Glucksberg, S. (1998). Understanding metaphors. Current Directions in Psychological Science, 7(2), 39-43. https://doi.org/10.1111/1467-8721.ep13175582

Glucksberg, S., \& Keysar, B. (1990). Understanding metaphorical comparisons: Beyond similarity. Psychological Review, 97(1), 3. https://doi.org/10.1037/0033-295X.97.1.3

Glucksberg, S., Newsome, M. R., \& Goldvarg, Y. (2001). Inhibition of the literal: Filtering metaphor-irrelevant information during metaphor comprehension. Metaphor and Symbol, 16(3-4), 277-298. https://doi.org/10.1080/10926488.2001.9678898

Glucksberg, S., \& Haught, C. (2006). Can Florida become like the next Florida? When metaphoric comparisons fail. Psychological Science, 17(11), 935-938. https://doi.org/10.1111/j.1467-9280.2006.01807.x

Glucksberg, S. (2011). Understanding metaphors: The paradox of unlike things compared. In Affective Computing and Sentiment Analysis (pp. 1-12). Springer, Dordrecht. https://doi.org/10.1007/978-94-007-1757-2_1

Grice, H. P. (1975). Logic and conversation. In Speech Acts (pp. 41-58). Brill. https://doi.org/10.1163/9789004368811_003

Grice, H. P. (1978). Further notes on logic and conversation. In Pragmatics (pp. 113-127). Brill. https://doi.org/10.1163/9789004368873_006

Grindstaff, F. L., \& Muller, A. L. (1975). The national assessment of literature: Two reviews. Research in the Teaching of English, 80-106.

Keil, F. C. (1986). Conceptual domains and the acquisition of metaphor. Cognitive Development, 1(1), 73-96. https://doi.org/10.1016/S0885-2014(86)80024-7

Miller, G. A. (1974). Toward a third metaphor for psycholinguistics. 
Miller, G. A., \& Johnson-Laird, P. N. (1976). Language and perception. Belknap Press. https://doi.org/10.4159/harvard.9780674421288

Miller, G. A., \& Glucksberg, S. (1988). Psycholinguistic aspects of pragmatics and semantics. Steven's Handbook of Experimental Psychology, 417-472.

Nippold, M. A., Leonard, L. B., \& Kail, R. (1984). Syntactic and conceptual factors in children's understanding of metaphors. Journal of Speech, Language, and Hearing Research, 27(2), 197-205. https://doi.org/10.1044/jshr.2702.197

Ortony, A. (1979). Beyond literal similarity. Psychological review,86(3), 161. https://doi.org/10.1017/CBO9781139173865

Ortony, A., \& Andrew, O. (Eds.). (1993). Metaphor and thought. Cambridge University Press.

Pearson, B. Z. (1990). The comprehension of metaphor by preschool children. Journal of child language, 17(1), 185-203. https://doi.org/10.1017/S0305000900013179

Piaget, J. (1955). The construction of reality in the child. Journal of Consulting Psychology, 19(1), 77. https://doi.org/10.1037/h0038817

Piaget, J., \& Inhelder, B. (1969). The psychology ofthe child. Trans. Helen Weaver. New York: Basic Books.

Pollio, M. R., \& Pollio, H. R. (1974). The development of figurative language in children. Journal of Psycholinguistic Research, 3(3), 185-201. https://doi.org/10.1007/BF01069237

Pouscoulous, N. (2011). Metaphor: For adults only?. Belgian Journal of Linguistics, 25(1), 51-79. https://doi.org/10.1075/bj1.25.04pou

Reynolds, R. E., \& Ortony, A. (1980). Some issues in the measurement of children's comprehension of metaphorical language. Child Development, 1110-1119. https://doi.org/10.2307/1129551

Richard, I. A. (1965). The philosophy of rhetoric. Oxford University Press.

Searle, J. R., \& Searle, J. R. (1969). Speech acts: An essay in the philosophy of language (Vol. 626). Cambridge University Press. https://doi.org/10.1017/CBO9781139173438

Seidenberg, P. L., \& Bernstein, D. K. (1986). The comprehension of similes and metaphors by learning disabled and nonlearning-disabled children. Language, Speech, and Hearing Services in Schools, 17(3), 219-229. https://doi.org/10.1044/0161-1461.1703.219

Sperber, D., \& Wilson, D. (2008). A deflationary account of metaphors. The Cambridge Handbook of Metaphor and Thought, 84, 105. https://doi.org/10.1017/CBO9780511816802.007

Sweet, J. A. (1974). An analysis of the writing of elementary children, grades four through six, to determine the relationship between specified genre and the development and use of figurative language (Doctoral dissertation, Indiana University).

Tversky, A. (1977). Features of similarity. Psychological Review, 84(4), 327. https://doi.org/10.1037/0033-295X.84.4.327

Thomas, M. S., Van Duuren, M., Purser, H. R., Mareschal, D., Ansari, D., \& Karmiloff-Smith, A. (2010). The development of metaphorical language comprehension in typical development and in Williams syndrome. Journal of Experimental Child Psychology, 106(2-3), 99-114. https://doi.org/10.1016/j.jecp.2009.12.007

Vosniadou, S. (1987). Children and metaphors. Child development, 870-885. https://doi.org/10.2307/1130223

Vosniadou, S., \& Ortony, A. (1986). Testing the metaphoric competence of the young child: Paraphrase versus enactment. Human Development.

Vosniadou, S., \& Ortony, A. (1983). The emergence of the literal-metaphorical-anomalous distinction in young children. Child Development, 154-161. https://doi.org/10.2307/1129872

Vosniadou, S., Ortony, A., Reynolds, R. E., \& Wilson, P. T. (1984). Sources of difficulty in the young child's understanding of metaphorical language. Child Development, 1588-1606. https://doi.org/10.2307/1130028

Wearing, C. (2010). Autism, metaphor and relevance theory. Mind \& language, 25(2), 196-216. https://doi.org/10.1111/j.1468-0017.2009.01386.x

Winner, E., Rosenstiel, A. K., \& Gardner, H. (1976). The development of metaphoric understanding. Developmental Psychology, 12(4), 289. 
Winner, E., Engel, M., \& Gardner, H. (1980). Misunderstanding metaphor: What's the problem?. Journal of Experimental Child Psychology, 30(1), 22-32. https://doi.org/10.1037/0012-1649.12.4.289

Wiig, E. H., \& Semel, E. M. (1984). Language assessment and intervention for the learning disabled. Braille/Taping Service, Washington Library for the Blind and Physically Handicapped. https://doi.org/10.1016/0022-0965(80)90072-7

\section{Copyrights}

Copyright for this article is retained by the author(s), with first publication rights granted to the journal.

This is an open-access article distributed under the terms and conditions of the Creative Commons Attribution license (http://creativecommons.org/licenses/by/4.0/). 